\title{
Where Have All the Flowers Gone .... Personal Brand Communication of Thai Famous Independent singer
}

\author{
Karittha Ungphakorn \\ Faculty of Communication Arts, University of the Thai Chamber of Commerce, Bangkok 10400, Thailand
}

\begin{abstract}
.
The study research "Where Have All the Flowers Gone .... Personal Brand Communication of Thai Famous Independent singer." To study the problem of marketing communication problems caused by changing environment in the modern music industry in Thailand, using qualitative research. The researcher has interviewed three prominent Thai independent singers, Mr. Saharat Sangkapricha Mr. Wongsakorn Ratsamitat. The study found that in the past decade from 1983 until 1997, main product of the music industry was the recording of the artist's album. Using the marketing communication tools of the artist through the tools of the mainstream media, including music videos, concerts, and music programs. Consumers will only be able to access the brand from a communications planner and the owner of the media. In the present era, from 1998 to date, the development of technology affected consumer behavior. The consumers can listen to free music and reach out to the artists on the online media channel. Products in the music industry shifted from selling music albums to music files and selling music streaming on online channels. Thus, marketing communications transform into online media use. The famous independent singers set up a marketing plan for themselves. And the system of music companies business has decreased.
\end{abstract}

Keywords: music, kong saharat, song, facebook, ton wongsakorn 


\section{Introduction}

Music is considered a manmade creative, economic innovation that requires creative thinking. As a result, there are enhanced intellectual property products stemming from songs like an album in cassette tape form, to CD album to MP3 (Supsinwiwat, 2017). Finally, we can listen to music via streaming services in various online social media platforms.

Because of these innovations, the music industry is interrupted from changing of consumer behavior. Music industry in turn, has to adjust itself in many ways like producing music products and marketing communications. This statement applies to both contracted and independent singers.

\section{Thai music business}

Thai music business is comprised of many factors like production, marketing planning, public relations, sales, advertising, sponsorship and distribution. All these need to work together to plan the whole product launch process, starting from music production, singer's identity creation. Although by nature the song has an average life of 3-6 months, which is not long, consumers buy the singer's voice and image. So, singer has to plan personal branding, image, reputation management and communication to prolong popularity. Every factor has to be coherent.

The growth of pop music business in Thailand has started to develop since 1967 and continued to grow and reach its peak during 1983-1997. This is a result of exposure to Western culture and a starting point of pop music acceptance among Thai people, until it has gradually become the industry. Main target groups are teenagers. (Phichaipat, 2010).

The beginning of music business in Thailand came from the success of string band type which has reached popularity peak in 1979, when the sales hit as high as 1 hundred thousand copies for the first album. The following album, ExO, was sold for 1 million copies, breaking all sales record in Thailand (Limpichai, 1989). So, music companies are born and grown into a big business. Two high-performance companies are RS PCL and GMM Grammy PCL. Subsidiaries have been set up to support production of a wide range of music, such as, rock music, dance music etc. With public relation planning and marketing, singers and music reached consumers, especially teenagers widely during that time.

During that period, quantity of copies sold was the measurement of marketing success. Any album with more than one million copies sold was considered successful. The following marketing tactic was to issue a special album as a collection copy for fans in the occasion of celebrating 1 million copies sold, may be by the adding of extra song and changing of cover.

While the Thai music industry has changed dramatically nowadays, as a result of technology changes causing consumer behavior in music listening change. Working and management method of music companies, artists, and music industry workers have to change as well. There are many forms of internal adjustments like expanding to other businesses, staff downsizing, moving to other business like TV show production or direct TV business, as well as closing down the music production section, for survival. 
As a result of this change, the music industry has to adjust itself. Music production cannot be in the form of album like in a 'prosperous era'. Marketing communication with consumers also changes according to current consumer behavior, especially communication between singers and their fan clubs. This includes media used, communication forms including various communication strategic plans as well.

This article will demonstrate the personal brand communications model of Thai famous independent singers with strong personal brand that has been popular since the 'prosperous era' until present, which can be developed as a model of personal brand management in the long term.

\section{Methodology}

The objective is to study the marketing communication of personal brand methods of popular Thai independent singers from the prosperous era amidst the current disruption of music industry. The research methodology is done by literature review, using three concepts, namely the concept of personal branding, marketing communication and the concept of the Facebook fan page for analysis. Qualitative research methods used are in-depth interviews and nonparticipatory observations in the marketing communication of Thai famous singers.

The researcher determined specific key informant to be two Thai famous independent singers, who were popular from the prosperous era to the present, in the span of not less than 30 years, with continuous albums or performances. They are Mr. Saharat Sangkapricha and Mr. Wongsakorn Ratsamitat.

\section{Research results}

Research results in accordance with the objectives of the study will present the marketing communication planning process, which has a total of 8 steps, starting with the SWOT analysis of the market situation, which is summarized in the following table. 2.1.1 Market situation analysis

\section{Strengths}

1. Famous and strong personal brand

2. There is a loyal fan club.

3. Songs from previous album are still popular as timeless songs.

\section{Weakness}

1. Consumers have change listening behavior from CDs to online.

2. New album production has decreased, single song is issued instead

3. The singer requires privacy as before. 


\section{Opportunities}

1. Consumers still want to watch live performances, concerts or work on various programs.

2. Fans like to see their identity, interview and be able to reach the singer rather than watching advertisements or public relations.

3. The media has online programs on website or mobile application.

4. Consumers have music listening behavior through online media.

5. Online media can share and forward information quickly.

6. The media needs a lot of content and variety.

\section{Threats}

1. Online media means less privacy

2. Online media can create fake identities or disguise as other people.

3. Consumers have unlimited information need.

4. Consumers can present information via their own channels.

5. Advertising media is expensive and high competition

6. There are many media that cannot be watched at the same time.

\subsubsection{Target group}

Thai famous independent singers set the same target group as fans that used to follow various performances in the past, without determining specific criteria such as age, gender or any demographic characteristics. They divided the target groups according to stakeholders but focus on the Fan club only.

\subsubsection{Communication objectives}

Thai famous independent singer define communication objectives for public relations of their events or work, to build personal brand awareness, creating consumer's demand for easy purchasing decision and creating interaction between famous singers and consumer

\subsubsection{Content design}

Thai famous independent singers have marketing communication team as well. Team members may be friends, personal managers, fans or family members. Material design for various announcements is incomplete and not as systematic as having a support from professional team. By the way, they use Facebook fan page to communicate with the fans only, which they may be a page admin for observation as well.

The content design emphasizes on good image to sustain credibility and avoid content that is personal life, such as daily living, pictures of private homes or introducing family member. The content focuses on providing good information according to accepted Thai culture and tradition, presenting image of a good person as social idols.

By defining 4 types of content:

1) Information of products and services: message inviting target groups to participate in activities or purchase products such as concerts, events, advertising, music through an interview 
on TV Program, a Radio program and pictures, clips and live through and social media, with details such as date, time, location and ticket price.

2) Contact information: Provide contact details and publicize through other social media. The singers with company contract only prepare for product and activity promotion. But independent singers have to prepare for channel of sales as well.

3) Schedule information: Present detailed event schedules of live shows, concerts, press conferences, product launches.

4) Information inviting society to do well: providing general information, including the glorification of the monarchy, showing respect to important people in the country or congratulating public figures for accomplishment. Also, political matters or imputing should be avoided.

\subsubsection{Marketing communication tools}

Thai famous independent singers use public relations tools via social media only, which does not give much importance to communication channel on social media and does not specify the exact content in presenting information. It is just announcement of activities that will happen and build engagement with the fan club only, they use social media to announce activities, to reach the target group because it is a modern media and social media is popular among most consumers.

\subsubsection{Budgeting}

Budgeting for marketing communication of Thai famous independent singers did not set any budgets for products (concerts or activities). They just communicate via social media (Facebook Fan Page) to their fan club only

\subsubsection{Collecting feedback}

Thai famous independent singers measured the response in communication from the target group by focusing on sales. Facebook fan page is the only social media communication channel used. Information analyzed is number of likes, number of shares and comments from the target group. They just check the use of @ (tag) or \# (hash tag) but do not record any feedback as evidence. Examination of information is only done periodically.

\subsubsection{Measurement and evaluation}

Thai famous independent singers assess the situation from sales and will communicate to boost sales from time to time. There are statistical evaluations of communication via Facebook, but there is no response to consumers in order to interact with the target group, which will consider the criteria for evaluation from 1. Insight information on Facebook fan page member as information of geography and behavior of target group and 2. Engagement of consumer focus on responding to comments, number of shares and likes

\subsection{Discussion}

The famous Thai independent singers have done marketing situation analysis as SWOT Analysis in marketing communication by considering advantages and disadvantages, using external factors such as the online media technology, consumer behavior or current situation to analyzed for the most efficient communication, not different from what Kotler and Armstrong (1999) said about business situations analysis by SWOT Analysis, using both internal and 
external factors affecting business operation to analyze the situation. There are various target groups defined according to stakeholder groups. The main target group is fan club. They are individuals categorized by consumer behavior. This is in line with Kotler and Armstrong (1999) said that groups are categorized by considering the characteristics of individual target. So, it is convenient to make communication decisions on content or messages and how to communicate. This is in accordance with the concept of Wongmonta (1997) that said the marketing communicator would be target grouping as focusing on behavioral science and psychology. They have to understand and can explain the behavior of the target group deeply. And they set four communication objectives: 1) to create brand awareness 2) to create demand for products 3) to facilitate the purchase and 4) to create participation. This is not different from Kotler and Armstrong (1999) stated that determining the objective of communication that is related to the perception and behavior of the target group, which needs the content and level of demand for awareness of the target group, must be able to perform and create success to focus on the response behavior.

Thai famous independent singers have a team to design content and produce various materials, emphasizing on the use of informal language to demonstrate friendliness to consumers, in line with Belch and Belch (1993) about the sender means the person who is responsible for communication about marketing news both of direct or indirect by the assignee to send the news should be influencers, who relay the message that can change attitudes, behavior and acknowledged. They should have good knowledge and ability in the proposed subject with being trusted, reliable, in order to create credibility, making the target group trust to buy more products.

Based on the concept of Kotler (1997), discussing the substance the communicator has to consider ways to speak to the target group in order to respond as needed and to create some ideas about the product for the audience, which corresponds to Thai famous singers, that design the content to attract the target group and to suit the media used, such as TV interviews, radio or live. They design pictures with detailed information by using informal language to make a relationship without informing personal matters.

For online communication, they use only Facebook Fan Page, as a presentation of activities of Thai famous singers and invite target group to join activities by showing the picture, VDO clip or live coverage of the performance with detail activity. This is consistent with the concept of Belch and Belch (1993) that says that the importance of presenting in the news format for effectiveness is to say something symbolically. So, news designers have to consider decision on headline, image and color to create interesting news through print media. Although according to such a concept, there will not be any information presented on print media only, but can connect with the presentation via Facebook fan page as well. Thai famous singers still maintain a strong personal branding by clear symbolic image. As a visual representation to emphasize their identity, they build credibility and confidence to maintain a good image and motivation to buy products and participate in activities.

For the marketing communication tools, Thai famous independent singers use public relation for marketing communication tools difference from Shimp (2010 referred to in Phattharaphinyohong, 2011) said that the marketing communication strategy for most effective, which is the use of multiple marketing communication tools, to stimulate behavior and decisionmaking process in the end. As well they focus mainly on public relations to create a good image and good relationship with various stakeholders such as journalists, TV, and radio program 
managers, which is consistent with the concept of Kotler (1997) that says public relations provide information to build good relationships and create a good image for the public. The presentation must be highly convincing and easy for consumers to expose to information in the form of regular public relations. So, it can be considered that Thai famous independent singers have to consider using tools that can reach many target groups at low cost

Incidentally, the results of the study found that it was not consistent with Kotler (1999) regarding the road-show, exhibition, and price reduction because personal brand is strong and popular among the target group. So, there is no need to use sales promotion tools to generate sales in a short period. This demonstrate that popular singers do not need to use every marketing activity to promote sales. But they should consider activities that conform to the brand image so as to maintain value in consumers' perception.

About the budgeting, Thai independent famous singers, that use only online media as a publicity tool with no expense and did not set any budget to communicate with their target group, which differs from what Kotler (2000) said that to allocate budget for communicating to Brand's target group.

According to Kotler (1999) discussed, when considering the effectiveness of marketing communication tools, there should be response collection from target recipients to measure perception, satisfaction or buying behavior. This is in accordance with the communication process of Thai famous independent singers because they have collected feedback by considering the number of sales and analytical information from social media to measure and evaluate. And also in accordance with Thipapal and Thipapal's concept (2010), that collecting feedback information from recipients is the message of response that returned to the sender, which is an assessment of the success of the communication process. However, even though the famous Thai independent singer has collected information to be considered but they did from time to time and it is not recorded as reference. If data are stored systematically, it can be checked, compared and used to develop communication in the next time.

The measurement and evaluation of Thai famous independent singers is made during the project and after the project implementation without assessment before starting a project. This is different from Kotler (1999) which says business operations should be evaluated at all times. There are 3 stages of evaluation before proceeding, during operation and postoperation. It may be because the famous singers understand behavior of their target group. So, they did not consider the assessment before communication but assess the situation and respond to consumers every time by analyzing all aspects of information, used as a guideline for developing content offerings and services in accordance with Thipapal and Thipapal's concept (2010) that said in measurement of marketing promotion action plan, the communicator has to measure the impact on the target what message topic that they can recall. How does the target group feel about that message? And the attitude that recipient has toward the product and company before and at present. Communicator should collect measurements of the response behavior of the recipients as well. 


\section{Conclusion}

I agree with many concepts that brands should have marketing communications to maintain the brand's reputation. Thai famous independent singers have been aware how to be seen as a good person in society and especially that Thailand is full of good culture and tradition for a very long time, which is different from other cultures. Thai culture is led by Buddhism, Royal Institution and seniority. This is different from that other culture and tradition. In brand management and brand communication, although marketing planning and communication strategies are not different from general theories, the content design is very important for building and maintaining brand reputation more. Personal branding has to focus on the needs and behavior of the target group especially for the context of Thai society.

The study also found that presenting positive information of personal branding is very important to create a good image. The showing loyalty to the monarchy and sincere sympathy for the current situation and showing friendly and familiar by using informal language will be easier to gain response from the target group.

Moreover, they should avoid expressing negative or one-sided political views, and not having to disclose privacy to the public, which will build the needs of the target group to access and ready to receive more information of each marketing communication from Personal Branding

\section{Acknowledgment}

This paper and the study behind it would not have been possible without the exceptional support of my professor, Jantima Kheokao. Her enthusiasm, knowledge and exact attention to detail have been an inspiration and kept my work on track from my first idea to the final draft of this paper. I would like to express my special thanks to Mr. Saharat Sangkapricha and Mr. Wongsakorn Ratsamitat, my key informants, who have been behind this study and provide more information with unfailing patience in answering numerous questions, Ms.Aroonee Sirivadhna who advised the information of the language context, Mrs.Pantip Ungphakorn, my beautiful mother who always cared for me, and the last important one is GOD who is my wonderful counselor.

The study of Doctor of Communication Arts in Marketing Communication at the University of the Thai Chamber of Commerce has proved that is interdisciplinary, which can bring knowledge to blend with other science as well as a trend, which should give priority and should convey this knowledge to be useful for working in various fields. 


\section{References}

Belch, George E. and Blech Michael A. (1993). Introduction to Advertising and Promotion: An Integrated Marketing Communications Perspective. 2d ed. Boston, Mass.: Richard D. Irwin, Inc.

Kotler, P. (1999) Marketing Management: Analysis, Planning, Implementation and Control. 9th Edition, Prentice Hall College Inc.

Kotler, P. and Armstrong, G. (1999). Principle of marketing (8th ed.). Upper saddle river, N.J.: Prentice-Hall International.

Kotler, Philip. (1997). Marketing Management (9 $9^{\text {th }}$ ed.). New Delhi: Prentice-Hall of India.

Kotler, Philip. (1997). Marketing Management: Analysis planning, implementation and control. 9th ed. Upper saddle river, New Jersey: Prentice-Hall. Inc.

Kotler, Philip. (2000) Marketing management. The millennium ed. upper saddle river, New Jersey: Prentice-Hall. Inc.

Limpichai, S. (1989). The Impact or the Tape Cassette Business on Creativity of Thai Popular Song. Master of Arts, Chulalongkorn University, Bangkok.

Pattharapinyophong, K. (2011). Integrated marketing communications planning of Asian Property Development Public Company Limited. Thesis, Thammasat University: Photocopy

Pichaiphaet, N. (2010). The Adapting Paradigm of the Thai Music Industry. Bangkok: Cultural Management College of Innovation Thammasat University.

Rasmidathe, W. (n.d.). ton.wongsakorn. [Online] Retrieved May 4, 2019, from facebook. Available: https://www.facebook.com/ton.wongsakorn

Sangkapricha, K. S. (November 2011). Kong Saharat Fanpage. [Online] Retrieved May 4, 2019, from kongsaharatfanpage. Available: https://www.facebook.com/kongsaharatfanpage/

Supsinwiwat, N. (2017). Music Industry in Thailand 4.0. Journal of Social Communication Innovation, 157-167.

Thipapal D. and Thipapal T. (2010). Marketing communications. Bangkok: Bansomdejchaopraya Rajabhat University

Wongmontha, S. (1997). Marketing communication ... indispensable components for success. Bangkok: A.N. Printing, writing 